\title{
Sex-specific association of metabolic risk factors with brain ischemic lesions by severity and location
}

\author{
Hailuan Zeng ${ }^{1,2}$, Weibin Shi ${ }^{3}$, Wenhai Jiang ${ }^{4}$, Shengxiang Rao ${ }^{5}$, Beijian Huang ${ }^{6}$, Hongmei Yan ${ }^{1,2^{*}}$ and Xin Gao ${ }^{1,2^{*}}$
}

\begin{abstract}
Background: Males and females exhibit significant differences in metabolism and in brain ischemic stroke and different features of brain ischemic lesions are related to different health outcomes. It is critical to understand sex differences in their associations to optimize prevention and intervention for both sexes. We aimed to investigate the sex-specific association of metabolic risk factors with brain ischemic lesions by severity and location.
\end{abstract}

Methods: Five thousand seven hundred ninety-one participants who underwent comprehensive health examinations between Jan. 1, 2017, and Dec. 31, 2017, were enrolled. Clinical and laboratory data about metabolic risk factors were obtained. Brain ischemic lesions were further categorized by severity (mild ischemic lesions or severe infarct lesions) and location (strictly lobar or deep brain/infratentorial areas) based on brain magnetic resonance imaging reports. Sex- and age-specific detected rates were calculated, and generalized linear models and multinomial logistic regression were used to analyze the associations between metabolic risk factors and the presence, severity, and location of ischemic lesions stratified by sex.

Results: A total of 2712 (46.8\%) participants had at least one brain ischemic lesions. Age (adjusted OR, 1.10 [1.101.11], $p<0.001$ ) and hypertension (adjusted OR, 1.42 [1.22-1.64], $p<0.001$ ) were generally associated with higher risks of brain ischemia in both sexes. Metabolic syndrome was associated with greater adjusted ORs for brain ischemia with different severity and location in men (adjusted ORs between 1.23 and 1.49) but not in women. Overweight and obesity were related to lesions located strictly in lobar in men (adjusted OR, 1.23 and 1.33, respectively) and lesions located in deep brain/infratentorial areas in women (adjusted OR, 1.57 and 2.26, respectively).

Conclusions: Metabolic syndrome was associated with brain ischemic lesions in men but not in women. Higher body mass index was related to ischemic lesions located in lobar in men and in deep brain/infratentorial areas in women. Its mechanisms remain to be further investigated.

Keywords: Sex-specific, Metabolic risk factors, Brain ischemic lesions, Severity, Location

\section{Background}

Brain ischemic lesions are frequently seen on brain magnetic resonance imaging (MRI) especially in the elderly population and have been reported to be associated with cognitive impairment [1], depression [2], stroke [3], mortality [4], and other adverse health outcomes [5]. Although the incidence of total stroke was greater among

\footnotetext{
* Correspondence: yan.hongmei@zs-hospital.sh.cn; happy20061208@126.com; zhongshan_endo@126.com

'Department of Endocrinology and Metabolism, Zhongshan Hospital, Fudan University, Shanghai, China

Full list of author information is available at the end of the article
}

males, females have a higher incidence of ischemic stroke and suffer worse outcomes relating to the severity of deficits and disability from stroke, yet they are more likely to survive [6-8]. There are many potential confounding factors, and more detailed research is needed to shed light on this complex relationship.

Findings in recent years suggest that not only the presence, but also the distribution, multiplicity, size, and side of brain ischemic lesions are related to different health outcomes and showed sex disparity in new infarct risk and cognitive decline [4, 9-12]. For example, results

(c) The Author(s). 2019 Open Access This article is distributed under the terms of the Creative Commons Attribution 4.0 International License (http://creativecommons.org/licenses/by/4.0/), which permits unrestricted use, distribution, and reproduction in any medium, provided you give appropriate credit to the original author(s) and the source, provide a link to the Creative Commons license, and indicate if changes were made. The Creative Commons Public Domain Dedication waiver (http://creativecommons.org/publicdomain/zero/1.0/) applies to the data made available in this article, unless otherwise stated. 
from the Chicago Health and Aging Project (CHAP) indicated that cortical, multiple, large, and bilateral infarcts were associated with lower cognition, particularly worse memory and perceptual speed [11]. All these results suggest that the features of brain ischemic lesions with sex differences might be indicative of different etiologies and pathogenic mechanisms that require investigations.

Risk factors for silent brain infarcts (SBI) have been extensively explored and well documented [5, 13-15]. Metabolic syndrome was reported to be strongly associated with risks of SBI and the adjusted odds ratio (OR) increased with the number of its components [16]. While advanced age and hypertension are well known to be associated with SBI as well as clinically defined ischemic stroke[15, 17-19], the relationships between brain infarctions and another single component of metabolic syndrome such as impaired fasting glucose and dyslipidemia remain controversial [16, 19-22]. Besides, fatty liver was recently pointed out to be an emerging predictor of stroke risk, severity, and outcome [23], yet there is limited information from large imaging studies on its association with brain ischemic lesions. Sex differences exist in nearly all of the components of metabolic syndrome, for example, males are more likely to have fat distribution in visceral areas while females in subcutaneous depots [24], females tend to have greater insulin sensitivity although they have greater percentage of fat mass than males, premenopausal females generally have higher HDL levels while males have higher plasma triglyceride levels, but lipoprotein profiles become more similar to males in postmenopausal females [25]. In this regard, we hypothesized that older age and hypertension were risk factors for brain ischemia in both sexes, while sex differences in associations between brain ischemic lesions and metabolic syndrome or its components may exist, especially taking lesion features such as severity and location into account. And we explored our hypothesis in a large crosssectional health examination data set.

\section{Methods}

\section{Study population}

Every year, about 100,000 people visit our Medical Examination Center in Zhongshan Hospital, Fudan University (Shanghai, China), for health examinations. Some of them were told by doctors in local community hospitals that they were at high risk of some certain diseases (e.g., cerebrovascular diseases) or are concerned about their health status and most of them are free of symptoms. From January to December in 2017, 13,007 subjects received a comprehensive health examination. After a preliminary consultation on demographic characteristics and a basic physical examination by trained physicians, they voluntarily undergo a series of blood tests, urine tests, and imaging examinations to screen for organ dysfunction, vascular disease, cancer, and other disorders. Their mean age was 47.9 (SD 11.3) years and $55.2 \%$ were men. About half of the subjects underwent brain MRI scan $(n=5860,45.1 \%)$. After excluding 6 subjects under 20 years old and 63 without complete data, 5791 subjects were enrolled in this study. The study was approved by the human research ethics committee of Zhongshan hospital, Fudan University, with a waiver of consent because this study did not involve contact with participants or any intervention.

\section{Clinical and laboratory data}

All subjects underwent comprehensive medical examinations by trained personnel with standardized instruments. Demographic and laboratory findings including age, sex, height, weight, blood pressure, fasting glucose, hemoglobin A1C (HbA1c), total cholesterol (TC), highdensity lipoprotein cholesterol (HDL-C), low-density lipoprotein cholesterol (LDL-C), triglycerides (TG), lipoprotein a $(\mathrm{Lp}(\mathrm{a}))$, aspartate aminotransferase (AST), alanine transaminase (ALT), gamma-glutamyl transferase (GGT), uric acid (UA), blood urea nitrogen (BUN), serum creatinine (Scr) were obtained and analyzed. All laboratory determinations were carried out using standard laboratory methods. For participants who had undergone more than one health checkup, data from the earliest examination were used.

\section{Liver ultrasonic examination}

Hepatic ultrasonographies (Vivid 7, GE Healthcare, Horten, Norway) were carried out by experienced sonologists. The diagnosis of fatty liver was made on the basis of characteristic ultrasonographic features consistent with dense and enhanced echogenicity of the liver parenchyma with obvious posterior attenuation of the echo, vessel blurring, and narrowing of the lumen of the hepatic veins [26].

\section{Brain MRI and ischemic lesions}

A 3.0-Tesla MRI scanner (GE Healthcare, Milwaukee, WI) was used to obtain T1-weighted, T2-weighted, fluid-attenuated inversion recovery (FLAIR), and diffusion-weighted imaging (DWI) sequences. After the MRI scan, formal reading reports containing image findings and diagnosis were given by two individual radiologists from the Department of Radiology in 2 days, disagreements were settled after discussion with a third board-certified radiologist. All of them were blinded to the subjects' clinical information and were unaware of the project goals. In brief, brain ischemic lesions were recognized as focal high-intensity areas identified on a T2-weighted image coinciding with low-intensity areas 
on a T1-weighted image, and ischemic/infarct ones with single/multiple locations were recorded. All kinds of brain ischemic lesions seen on MRI images were reported regardless of their size, whether they were symptomatic or silent, old or new. Screen results were extracted from the medical databases stored in the computer network center in our hospital. For researching convenience, brain ischemic lesions were categorized into mild ischemic or severe infarct lesions and into one of three locations: lobar (cortical gray and subcortical white matter of periventricular, centrum ovale, and corona radiate), deep brain (gray matter of basal ganglia and thalamus, and the white matter of corpus callosum, internal and external capsule), and infratentorial (brainstem and cerebellum) according to MRI reports. No distinction was made between participants with the size and number of ischemic lesions on their scan.

\section{Metabolic status definitions}

Hypertension was defined by a systolic blood pressure (SBP) $\geq 140 \mathrm{mmHg}$ or a diastolic blood pressure (DBP) $\geq 90 \mathrm{mmHg}$. Dyslipidemia was defined as increased total cholesterol $\geq 6.2 \mathrm{mmol} / \mathrm{L}$, LDL-C $\geq 4.1 \mathrm{mmol} / \mathrm{L}$, triglyceride levels $\geq 2.3 \mathrm{mmol} / \mathrm{L}$, or decreased HDL-C $<1.0$ $\mathrm{mmol} / \mathrm{L}]$ ]) [27]. Diabetes mellitus was defined as fasting plasma glucose $\geq 7.0 \mathrm{mmol} / \mathrm{L}$ or $\mathrm{HbA} 1 \mathrm{c} \geq 6.5 \%$, and prediabetes was defined as fasting plasma glucose between $5.6 \mathrm{mmol} / \mathrm{L}$ and $6.9 \mathrm{mmol} / \mathrm{L}$ or $\mathrm{HbA} 1 \mathrm{c}$ between $5.7 \%$ and $6.4 \%$. Fatty liver was categorized into mild to moderate fatty liver and severe fatty liver according to ultrasonic examination results. BMI was calculated from measured weight and height and categorized as follows: normal (BMI $\left.<24 \mathrm{~kg} / \mathrm{m}^{2}\right)$, overweight $\left(24 \mathrm{~kg} / \mathrm{m}^{2} \leq \mathrm{BMI}<\right.$ $\left.28 \mathrm{~kg} / \mathrm{m}^{2}\right)$, and obese $\left(B M I \geq 28 \mathrm{~kg} / \mathrm{m}^{2}\right)$. Subjects were labeled as having metabolic syndrome by the presence of three or more of the following: (1) obesity with a BMI $\geq$ $25 \mathrm{~kg} / \mathrm{m}^{2}$, (2) blood pressure $\geq 130 / 85 \mathrm{mmHg}$, (3) fasting glucose $\geq 100 \mathrm{mg} / \mathrm{dL}$ ( $5.6 \mathrm{mmol} / \mathrm{L})$, (4) triglyceride $\geq 150$ $\mathrm{mg} / \mathrm{dL}(1.7 \mathrm{mmol} / \mathrm{L})$, and (5) high-density lipoprotein cholesterol $<40 \mathrm{mg} / \mathrm{dL}(1.03 \mathrm{mmol} / \mathrm{L})$ in men and $<50$ $\mathrm{mg} / \mathrm{dL}(1.3 \mathrm{mmol} / \mathrm{L})$ in women [28].

\section{Statistical analysis}

All statistical analyses were performed using $\mathrm{R}$, version 3.4.4 ( $\mathrm{R}$ Programming). Continuous variables are expressed as mean (SD) or median [IQR], and categorical data are expressed as count (percentage). Student's $t$ test or the nonparametric Mann-Whitney $U$ test was used for intergroup comparisons of continuous data whereas the chi-squared test was used for comparisons of categorical variables. The prevalence and characteristics of ischemic lesions on MRI were calculated in 10year age strata.
At first, univariate generalized linear models were made to analyze the associations of age, sex, and metabolic risk factors with the presence of brain ischemic lesions followed by models adjusted for age and sex (age and sex were adjusted for each other), and a full model containing all covariates except for metabolic syndrome (to avoid collinearity) was applied. After that, generalized linear models and multinomial logistic regressions adjusted for all covariates except for sex were made stratified by sex to analyze the associations between metabolic status (except for metabolic syndrome, which results were adjusted for age only) and presence, severity (none, ischemic, infarct), and location (strictly lobar, deep brain, or infratentorial with or without lesions in lobar) of lesions. All statistical tests were two-tailed, and $p<0.05$ was considered statistically significant.

\section{Results}

\section{Participant characteristics}

A total of 5791 participants were included in the analysis. The mean (SD) age of the population was 48.8 (10.1) years with a range of 20-88 years, and 3395 (58.6\%) were men. Brain ischemic/infarct lesions were detected in $2712(46.8 \%)$ participants. Compared to females, males have higher BMI and higher incidence of metabolic syndrome including all its components (Table 1). The detected rates of ischemic lesions by severity and location stratified by sex and age groups are presented in Fig. 1. Sex distribution was balanced among age groups. In both sexes, the detected rates of brain ischemic/infarct lesions increased dramatically with age. Older women tended to have severe infarct lesions while lesions located in deep or infratentorial areas were more prevalent in older men (Fig. 1).

\section{Association of metabolic status with the risk of brain ischemic lesions}

In univariate generalized linear models, older age, hypertension, pre-diabetes, diabetes, overweight, obesity, fatty liver, and metabolic syndrome were strongly associated with the risk of harboring brain ischemic lesions on MRI. The ORs ranged between age 1.10 (95\% CI, 1.10-1.11) and diabetes 1.92 (95\% CI, 1.512.44), while the associations between the risk of harboring brain ischemic lesions and sex or dyslipidemia were of no significance (Table 2). After adjusting for age and sex, age (adjusted for sex), hypertension, overweight, obesity, and metabolic syndrome were still significant (Table 2). In a multiple analysis adjusted for all covariates, the difference was significant only for age and hypertension with adjusted ORs of 1.10 (95\% CI, 1.10-1.11) and 1.42 (95\% CI, 1.22-1.64), respectively (Table 2 ). 
Table 1 Baseline characteristics of the study population

\begin{tabular}{|c|c|c|c|c|}
\hline & Overall $(n=5791)$ & Female $(n=2396)$ & Male $(n=3395)$ & $p$ value \\
\hline Age, year & $48.8(10.1)$ & $49.2(10.4)$ & $48.6(9.92)$ & 0.024 \\
\hline $\mathrm{BMI}, \mathrm{kg} / \mathrm{m}^{2}$ & $24.0(3.34)$ & $22.7(3.12)$ & $25.0(3.19)$ & $<0.001$ \\
\hline $\mathrm{SBP}, \mathrm{mmHg}$ & $116(14.7)$ & $114(15.6)$ & $117(13.9)$ & $<0.001$ \\
\hline $\mathrm{DBP}, \mathrm{mmHg}$ & $78.6(9.5)$ & $76.1(9.3)$ & $80.4(9.2)$ & $<0.001$ \\
\hline Fasting glucose, $\mathrm{mmol} / \mathrm{L}$ & $5.16(1.19)$ & $5.02(0.97)$ & $5.26(1.32)$ & $<0.001$ \\
\hline $\mathrm{HbA} 1 \mathrm{C}, \%$ & $5.54(0.74)$ & $5.45(0.62)$ & $5.61(0.82)$ & $<0.001$ \\
\hline $\mathrm{TG}, \mathrm{mmol} / \mathrm{L}$ & $1.77(1.38)$ & $1.35(0.96)$ & $2.07(1.55)$ & $<0.001$ \\
\hline $\mathrm{TC}, \mathrm{mmol} / \mathrm{L}$ & $5.06(0.99)$ & $5.02(0.96)$ & $5.09(1.01)$ & 0.004 \\
\hline $\mathrm{HDL}-\mathrm{C}, \mathrm{mmol} / \mathrm{L}$ & $1.33(0.373)$ & $1.52(0.376)$ & $1.20(0.306)$ & $<0.001$ \\
\hline $\mathrm{N}-\mathrm{HDL}-\mathrm{C}, \mathrm{mmol} / \mathrm{L}$ & $3.73(1.01)$ & $3.50(0.96)$ & $3.89(1.02)$ & $<0.001$ \\
\hline $\mathrm{LDL}-\mathrm{C}, \mathrm{mmol} / \mathrm{L}$ & $2.96(0.875)$ & $2.90(0.862)$ & $3.01(0.882)$ & $<0.001$ \\
\hline $\mathrm{Lp}(\mathrm{a}), \mathrm{mg} / \mathrm{L}$ & $114[53.3,234]$ & $130[67.0,253]$ & $103[46.0,219]$ & $<0.001$ \\
\hline APOB, $g / L$ & $0.923(0.224)$ & $0.870(0.216)$ & $0.960(0.222)$ & $<0.001$ \\
\hline APOA-1, g/L & $1.52(0.269)$ & $1.62(0.268)$ & $1.45(0.247)$ & $<0.001$ \\
\hline $\mathrm{APOE}, \mathrm{mg} / \mathrm{L}$ & $45.7(16.7)$ & $44.3(14.3)$ & $46.6(18.2)$ & 0.002 \\
\hline$A L T, U / L$ & $20.0[13.5,31.1]$ & $14.5[10.8,20.9]$ & $25.1[17.6,37.5]$ & $<0.001$ \\
\hline AST, U/L & $21.0[17.4,26.0]$ & $19.0[16.0,23.0]$ & $22.5[19.0,28.0]$ & $<0.001$ \\
\hline GGT, U/L & $27.0[17.0,48.0]$ & $17.3[13.0,24.6]$ & $38.0[25.0,63.0]$ & $<0.001$ \\
\hline UA, umol/L & $339(90.0)$ & $273(61.3)$ & $386(77.1)$ & $<0.001$ \\
\hline BUN, mmol/L & $4.93(1.20)$ & $4.65(1.20)$ & $5.13(1.17)$ & $<0.001$ \\
\hline Scr, umol/L & $76.0(16.3)$ & $62.2(9.43)$ & $85.8(12.7)$ & $<0.001$ \\
\hline $\mathrm{CRP}, \mathrm{mg} / \mathrm{L}$ & $0.99[0.54,1.89]$ & $0.79[0.45,1.50]$ & $1.12[0.63,2.18]$ & 0.000 \\
\hline Hypertension, $n$ (\%) & $1205(20.8 \%)$ & $383(16.0 \%)$ & $822(24.2 \%)$ & $<0.001$ \\
\hline Dyslipidemia, $n$ (\%) & $2155(37.2 \%)$ & $521(21.7 \%)$ & $1634(48.1 \%)$ & $<0.001$ \\
\hline Pre-diabetes, $n(\%)$ & $1483(25.6 \%)$ & $567(23.7 \%)$ & $916(27.0 \%)$ & $<0.001$ \\
\hline Diabetes, $n(\%)$ & $299(5.2 \%)$ & $59(2.5 \%)$ & $240(7.1 \%)$ & $<0.001$ \\
\hline Mild to moderate fatty liver, $n(\%)$ & $1275(22.0 \%)$ & $345(14.4 \%)$ & $930(27.4 \%)$ & $<0.001$ \\
\hline Severe fatty liver, $n(\%)$ & $1200(20.7 \%)$ & 297 (12.4\%) & $903(26.6 \%)$ & $<0.001$ \\
\hline Overweight, $n(\%)$ & 2194 (37.9\%) & $605(25.3 \%)$ & $1589(46.8 \%)$ & $<0.001$ \\
\hline Obese, $n(\%)$ & $657(11.3 \%)$ & $139(5.8 \%)$ & $518(15.3 \%)$ & $<0.001$ \\
\hline Metabolic Syndrome, n (\%) & 1407 (24.3\%) & 358 (14.9\%) & 1049 (30.9\%) & $<0.001$ \\
\hline
\end{tabular}

\footnotetext{
Data presented as mean (SD) or median (IQR) and $n(\%)$
}

$B M I$ body mass index, SBP systolic blood pressure, $D B P$ diastolic blood pressure, $T G$ triglyceride, $T C$ total cholesterol, $H D L-C$ high-density lipoprotein cholesterol, $N$ $H D L-C$ non-high-density lipoprotein cholesterol, $L D L-C$ low-density lipoprotein cholesterol, $L p(a)$ lipoprotein a, $A L T$ alanine aminotransferase, $A S T$ aspartate aminotransferase, GGT gamma-glutamyl transferase, UA uric acid, BUN blood urea nitrogen, Scr serum creatinine, CRP C-reactive protein

\section{Brain ischemic severity and metabolic status}

Multinomial regression adjusted for all covariates showed that older age was strongly associated with the risk of brain ischemic lesions and infarct lesions and the adjusted ORs were almost the same in both sexes: 1.09 for ischemic lesions and 1.18 for infarct lesions. Hypertensive status was associated with an increased risk of harboring ischemic lesions in both female (adjusted OR, 1.48; 95\% CI, 1.14-1.93) and male (adjusted OR, 1.26; $95 \%$ CI, 1.04-1.52), as well as an increased risk of harboring infarct lesions (female adjusted OR, 1.47; 95\% CI, 1.01-2.14 and male adjusted OR, 2.02; 95\% CI, 1.55-
2.64). Overweight and obesity were significantly associated with a higher risk of harboring ischemic lesions but not infarct lesions in male (adjusted OR, 1.28 and 1.33 vs adjusted OR, 1.02 and 1.47), whereas those in female were not significant. Dyslipidemia, pre-diabetes, diabetes, and fatty liver were not significantly associated with harboring either brain ischemic lesions or infarct lesions in both sexes. A status of metabolic syndrome was found to have a harmful effect in male (adjusted ORs for ischemia and infarction were 1.25 [95\% CI, 1.06-1.48; $p$ value, 0.008 ] and 1.06 [95\% CI, 1.13-1.89; $p$ value, 0.003], respectively) but not in female (Fig. 2). 

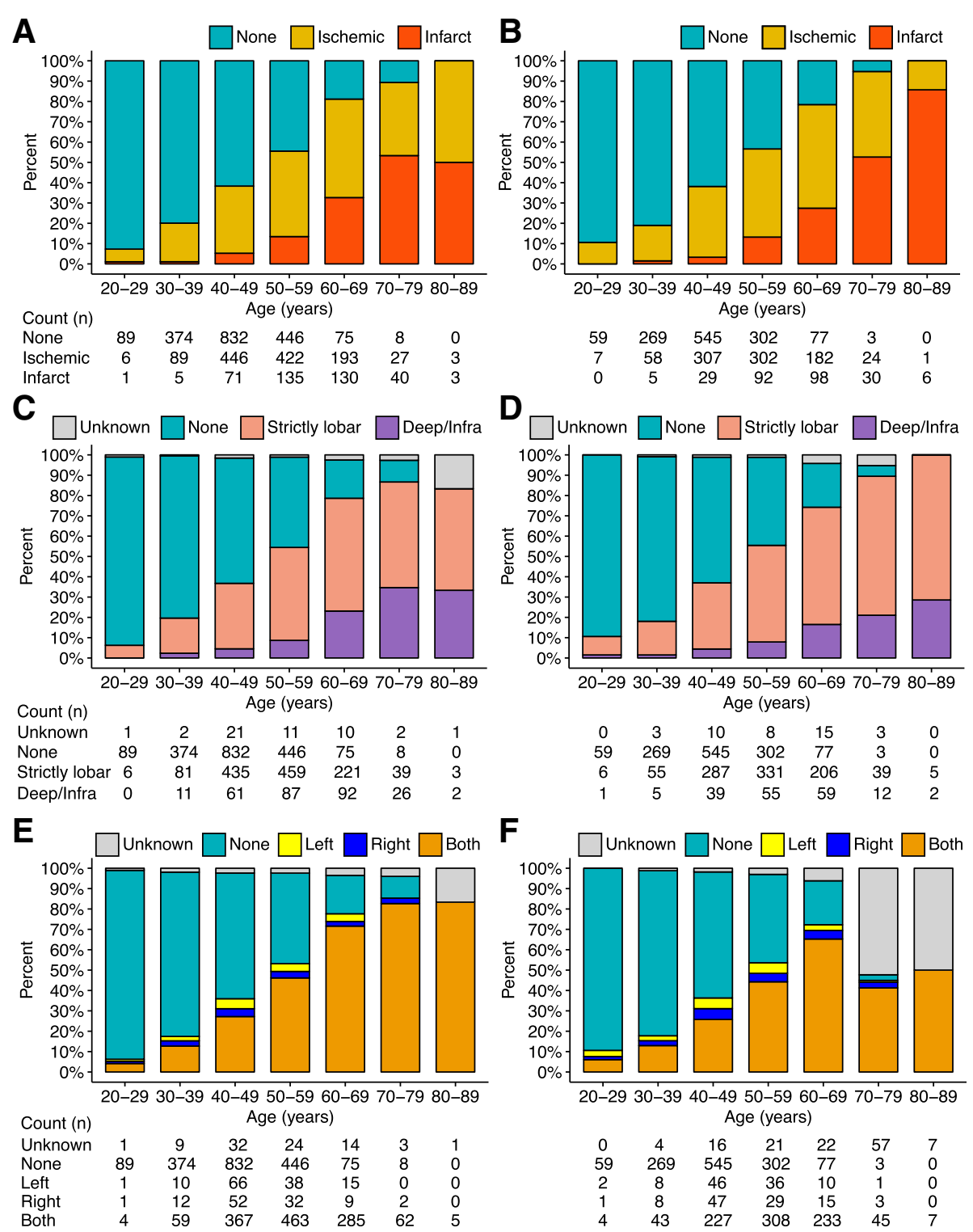

Fig. 1 Detection results of brain ischemic lesions stratified by age and sex. a, b Detected rate of brain ischemic and infarct lesion in male (a) and female (b) stratified by age. $\mathbf{c}, \mathbf{d}$ Location of brain ischemic/infarct lesion in male (c) and female (d) stratified by age. e, $\mathbf{f}$ Side of cerebral hemisphere of brain ischemic/infarct lesion in male (e) and female (f) stratified by age

\section{Brain ischemic lesion location and metabolic status}

The effect of metabolic status on brain ischemic lesion locations was also investigated with multinomial logistic regression adjusted for all covariates. Again, age increasement and hypertension were associated with higher ORs for lesions located both strictly in lobar and deep or infratentorial areas in both sexes. Additionally, overweight and obesity were associated with significantly greater ORs for lesions located strictly in lobar in male (adjusted OR, 1.23; 95\% CI, 1.02-1.48 and adjusted OR, 1.33; 95\% CI, 1.02-1.74, respectively) and lesions located in deep brain or infratentorial areas in female (adjusted OR, 1.57; 95\% CI, 1.06-2.35 and adjusted OR, 2.26; 95\%
CI, 1.17-4.40, respectively). After adjusting for age, metabolic syndrome had a higher adjusted OR for lesions located strictly in lobar (adjusted OR, 1.23; 95\% CI, $1.04-1.45 ; p$ value, 0.017 ) and in deep brain or infratentorial areas (adjusted OR, 1.49; 95\% CI, 1.13-1.98; $p$ value, 0.005$)$ in male but showed no significance in female (Fig. 3).

\section{Discussion}

In a population of 5791 Chinese undergoing medical examinations, a total of $2712(46.8 \%)$ participants had at least one brain ischemic lesion. The detected rate increased steadily with age and was balanced in males and 
Table 2 Relationships between metabolic status and the risk of harboring brain ischemic lesions

\begin{tabular}{|c|c|c|c|c|c|c|}
\hline \multirow[t]{2}{*}{ Variables } & \multirow{2}{*}{$\begin{array}{l}\text { Unadjusted } \\
\text { OR (95\% Cl) }\end{array}$} & \multirow{2}{*}{$\begin{array}{l}p \\
\text { value }\end{array}$} & \multicolumn{2}{|c|}{ Adjusted for age and sex } & \multirow{2}{*}{$\begin{array}{l}\text { Multiple } \\
\text { OR (95\% Cl) }\end{array}$} & \multirow{2}{*}{$\begin{array}{l}P \\
\text { value }\end{array}$} \\
\hline & & & $\mathrm{OR}(95 \% \mathrm{Cl})$ & $p$ value & & \\
\hline Age & $1.10(1.10-1.11)$ & $<0.001$ & $1.10(1.10-1.11)$ & $<0.001$ & $1.10(1.10-1.11)$ & $<0.001$ \\
\hline Male & $0.95(0.85-1.05)$ & 0.312 & $1.00(0.89-1.12)$ & 0.974 & $0.94(0.83-1.06)$ & 0.308 \\
\hline Hypertension & $1.91(1.68-2.17)$ & $<0.001$ & $1.42(1.23-1.64)$ & $<0.001$ & $1.42(1.22-1.64)$ & $<0.001$ \\
\hline Dyslipidemia & $1.06(0.96-1.18)$ & 0.257 & $1.04(0.92-1.17)$ & 0.559 & $1.02(0.90-1.16)$ & 0.720 \\
\hline Pre-diabetes & $1.67(1.48-1.88)$ & $<0.001$ & $0.90(0.79-1.03)$ & 0.143 & $0.86(0.75-0.99)$ & 0.041 \\
\hline Diabetes & $1.92(1.51-2.44)$ & $<0.001$ & $0.94(0.72-1.23)$ & 0.658 & $0.90(0.69-1.18)$ & 0.453 \\
\hline Overweight & $1.31(1.18-1.47)$ & $<0.001$ & $1.14(1.00-1.29)$ & 0.047 & $1.13(0.99-1.30)$ & 0.074 \\
\hline Obesity & $1.28(1.08-1.51)$ & 0.005 & $1.23(1.01-1.49)$ & 0.035 & $1.24(1.00-1.54)$ & 0.052 \\
\hline Mild to moderate fatty liver & $1.30(1.15-1.49)$ & $<0.001$ & $1.14(0.99-1.32)$ & 0.074 & $1.06(0.91-1.24)$ & 0.475 \\
\hline Severe fatty liver & $1.15(1.01-1.31)$ & 0.042 & $1.00(0.86-1.16)$ & 0.974 & $0.89(0.74-1.06)$ & 0.181 \\
\hline Metabolic Syndrome & $1.46(1.29-1.65)$ & $<0.001$ & $1.20(1.05-1.38)$ & 0.007 & - & - \\
\hline
\end{tabular}

Values represent estimated odds ratios with $95 \%$ confidence interval for any brain ischemic lesions with reference to normal status

females. The prevalence of hypertension, pre-diabetes, diabetes, fatty liver, overweight, and metabolic syndrome was higher in males. Older age and hypertension were major risk factors for brain ischemic lesions in both sexes while metabolic syndrome showed significantly greater adjusted ORs in men but not in women. Overweight and obesity were related to lesions located strictly in lobar in men and lesions located in deep brain or infratentorial areas in women.

The prevalence of brain ischemic/infarct lesions in our study was relatively high compared with previous works on SBI $[13,15,29-32]$. There are two possible reasons for these inconsistent findings: one is that unlike healthy participants receiving health checkups paid by their employers in some other studies, the majority of the participants who visited our examination center and asked for a brain MRI scan were concerned about their worse health status such as diabetes, obesity, and other comorbidities; the other is that we reported all kinds of brain ischemic lesions seen on MRI images regardless of their size, whether they were symptomatic or silent, old or new, while others focusing on SBI included only lesions with the size of $3-15 \mathrm{~mm}$ and were silent ones and subjects with stroke, transient ischemic attack, or other cardiovascular diseases (and were more likely to have brain infarctions) were excluded.

As expected, older age and hypertension were main risk factors for brain ischemic lesions regardless of the severity and location, which was in accordance with similar studies [19, 29-31]. Studies from Korea and

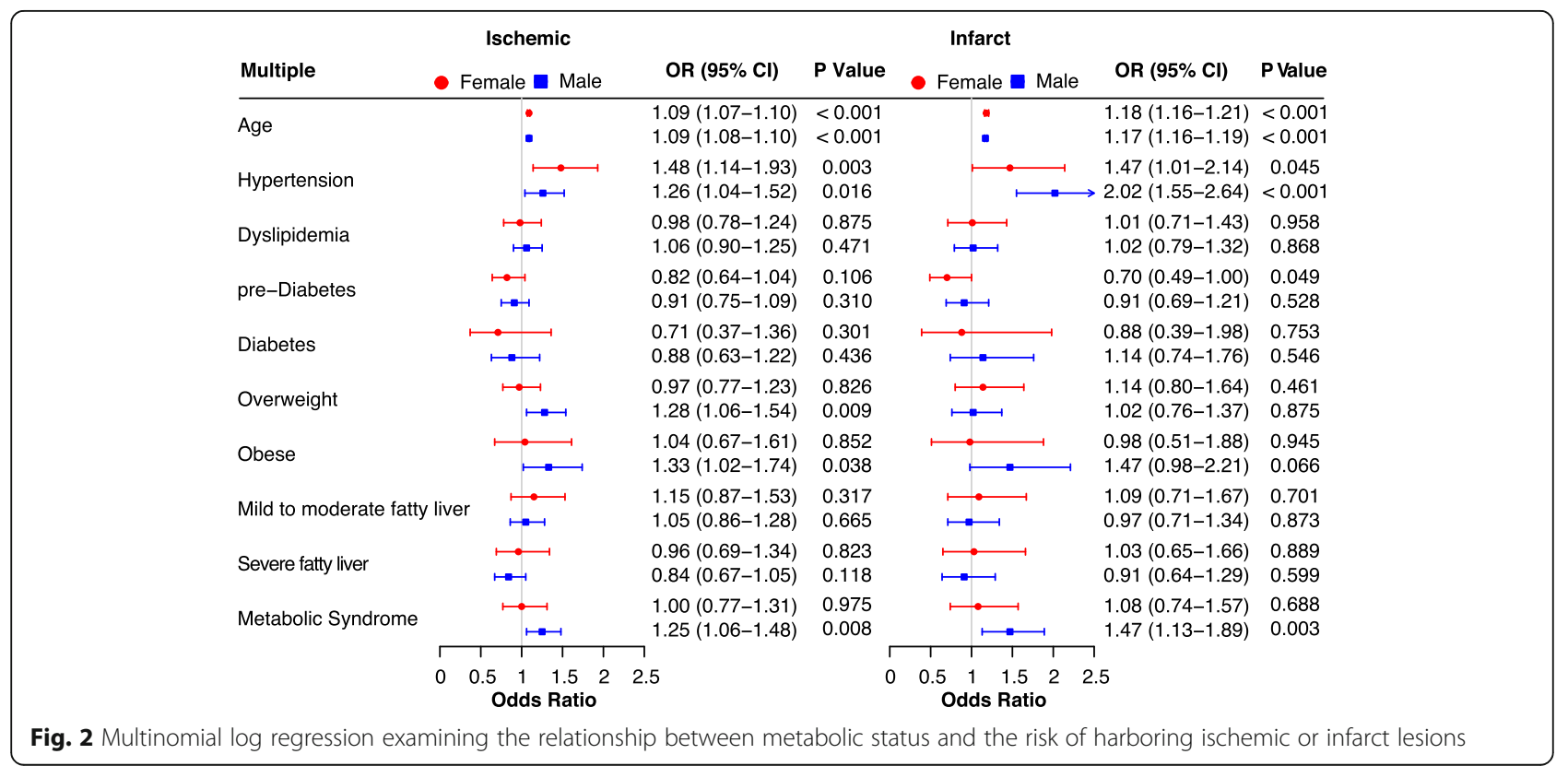




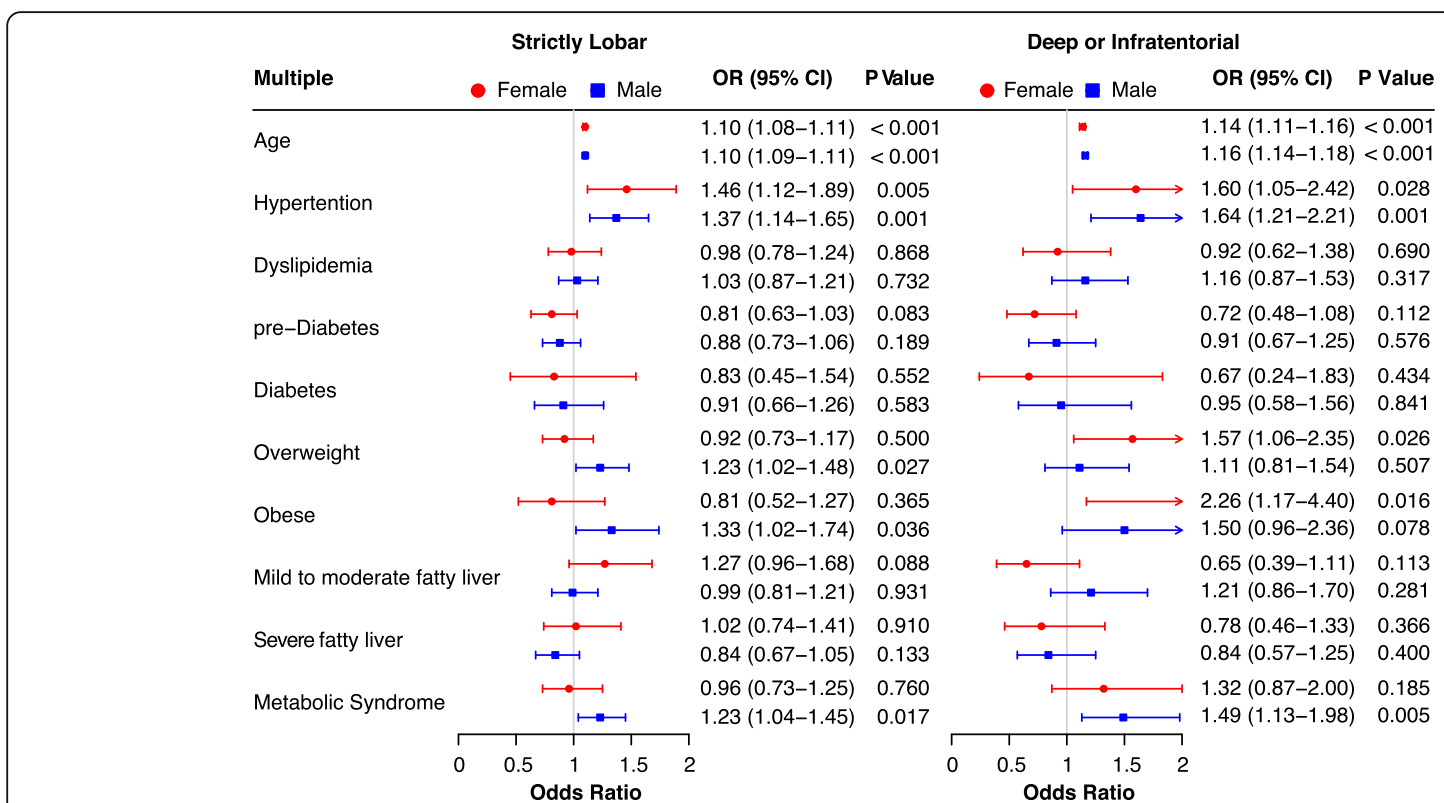

Fig. 3 Multinomial log regression examining the relationship between metabolic status and the location of brain ischemic lesions

Japan reported adjusted ORs of 1.06-1.09, 1.54-3.75, and $1.68-2.43$ for the associations between silent brain infarctions and age, elevated blood pressure, and metabolic syndrome, respectively $[16,19,21]$. Similarly, in our study, age, hypertension, and metabolic syndrome showed significance in multinomial regression models with adjusted ORs of 1.10 (95\% CI, 1.10-1.11), 1.42 (95\% CI, 1.22-1.64), and 1.20 (95\% CI, 1.05-1.38), respectively. The associations between dyslipidemia, prediabetes, diabetes, overweight, obesity, and fatty liver and the presence of brain ischemic or infarct lesions in the general population showed significantly higher unadjusted ORs but were insignificant after adjustment, which might indicate that they might not be independent risk factors for brain ischemia.

Metabolic syndrome was a risk factor for brain ischemia in men but not in women after adjusting for age. This was in accordance with a few studies indicated no increased risk of metabolic syndrome-related ischemic stroke especially in women [33, 34], although some showed that both males and females with metabolic syndrome are at higher risks for stroke [35]. The inconsistent results may be explained by different study designs and definitions and considering different variables for adjustment. It is surprising that little is known about the sex differences in the relationships between metabolic syndrome and silent brain ischemia or infarction. In our study, most of the participants with brain ischemic lesions were at an early stage with no symptoms, and our results suggested that metabolic syndrome might play a role in brain ischemia before the onset of stroke in men. It is noteworthy that male participants were at worse metabolic status (Table 1), but the detected rates of lesions were balanced in both sexes (Fig. 1), which implied that brain ischemia in females was more influenced by age, especially in those older than 50 years.

Another interesting finding was the disparate impacts of overweight and obesity (calculated from BMI) on lesion severity and location in different sexes. Higher BMIs were associated with ischemic lesions but not infarct ones in male participants, which might give a hint that it was a trigger factor for brain ischemia but would not lead to advanced infarctions. Surprisingly, higher BMIs were significantly related to a higher risk of lesions located strictly in lobar in men and lesions located in deep brain or infratentorial regions in women. Some publications have addressed the relationship between BMI and intracranial location of the brain hemorrhage [36], but there was a lack of information on the sexspecific associations between BMI and location of brain ischemia. A prospective case-control study in Spain reported that increased BMI was related to a lower risk of stroke in men and abdominal obesity was associated with ischemic stroke in women [37]. Unfortunately, data about abdominal obesity including waist circumference and waist-to-height ratio of the participants were not obtained in the present study, but our results emphasized the need to uncover sex differences to better understand the underlying mechanisms. Sex-related differences in fat distribution and its impacts on cardiovascular diseases are well established, and thus it would be interesting to further investigate whether sex-related disparity of fat distribution is associated with specific locations of brain ischemia and ischemic stroke. 
The strength of our study included the large number of participants representing a broad range of age (20-88 years old), the detailed analysis of brain ischemic lesions including the presence, severity, and location, and the use of age- and sex-stratified metabolic status. Our study had several limitations. First, this was a secondary analysis of medical examination data, and thus the size, multiplicity, shape, and location of the brain lesions could not be reviewed and scored, yet the reports were given by experienced radiologists and checked by clinicians in our hospital who were blinded to the study. Second, we did not exclude participants who had taken medications, which might have underestimated the associations of brain ischemic lesions with hypertension, diabetes, or dyslipidemia. Third, information on smoking status, drinking status, physical activities, and some other comorbidities such as atrial fibrillation [38, 39], carotid artery stenosis, and renal dysfunction [40] of the participants were not available and might be confounders or mediators. Another limitation to our study is the observational design and the inability to observe causal effects.

\section{Conclusions}

In summary, this study found that older age and hypertension were generally associated with an elevated risk of brain ischemia in both sexes while metabolic syndrome was related to higher risk in men but not in women. Higher BMI was associated with ischemic lesions located strictly in lobar in men and lesions located in deep brain or infratentorial regions in women. Sexrelated differences in associations of obesity with brain ischemic areas need further investigations to better understand the underlying pathological processes and mechanisms.

\section{Acknowledgements}

Not applicable.

\section{Authors' contributions}

XG conceived and designed the study, interpreted data, and revised the manuscript. HY obtained and interpreted data and revised the manuscript. $\mathrm{HZ}$ conducted statistical analysis, interpreted the results, and drafted the manuscript. WS performed physical examinations and collected data. WJ preserved and exported the data. SR performed brain MRI scan and reported the results. BH performed liver ultrasonography and reported the results. All authors read and approved the final manuscript.

\section{Funding}

The study did not receive funding.

\section{Availability of data and materials}

The datasets generated and/or analyzed during the current study are available from the corresponding author on reasonable request.

\section{Ethics approval and consent to participate}

The study was approved by the human research ethics committee of Zhongshan Hospital, Fudan University, with a waiver of consent because this is a retrospective clinical study and did not involve contact with participants or any intervention.
Consent for publication

Not applicable.

\section{Competing interests}

The authors declare that they have no competing interests.

\section{Author details}

'Department of Endocrinology and Metabolism, Zhongshan Hospital, Fudan University, Shanghai, China. ${ }^{2}$ Fudan Institute for Metabolic Diseases,

Shanghai, China. ${ }^{3}$ Medical Examination Center, Zhongshan Hospital, Fudan University, Shanghai, China. ${ }^{4}$ Computer Network Center, Zhongshan Hospital, Fudan University, Shanghai, China. ${ }^{5}$ Department of Radiology, Zhongshan Hospital, Fudan University, Shanghai, China. ${ }^{6}$ Department of Ultrasonography, Zhongshan Hospital, Fudan University, Shanghai, China.

Received: 23 April 2019 Accepted: 5 August 2019

Published online: 22 August 2019

\section{References}

1. Vermeer SE, Prins ND, den Heijer T, Hofman A, Koudstaal PJ, Breteler MM. Silent brain infarcts and the risk of dementia and cognitive decline. N Engl J Med. 2003;348(13):1215-22. https://doi.org/10.1056/NEJMoa022066.

2. van Sloten $\Pi$, Sigurdsson $S$, van Buchem MA, Phillips $C L$, Jonsson PV, Ding J, et al. Cerebral small vessel disease and association with higher incidence of depressive symptoms in a general elderly population: the AGES-Reykjavik Study. Am J Psychiatry. 2015;172(6):570-8. https://doi.org/10.1176/appi.ajp.2 014.14050578

3. Gupta A, Giambrone AE, Gialdini G, Finn C, Delgado D, Gutierrez J, et al. Silent brain infarction and risk of future stroke: a systematic review and meta-analysis. Stroke. 2016;47(3):719-25. https://doi.org/10.1161/ strokeaha.115.011889.

4. Windham BG, Deere B, Griswold ME, Wang W, Bezerra DC, Shibata D, et al. Small brain lesions and incident stroke and mortality: a cohort study. Ann Intern Med. 2015;163(1):22-31. https://doi.org/10.7326/m14-2057.

5. van Veluw SJ, Shih AY, Smith EE, Chen C, Schneider JA, Wardlaw JM, et al. Detection, risk factors, and functional consequences of cerebral microinfarcts. Lancet Neurol. 2017;16(9):730-40. https://doi.org/10.1016/s14 74-4422(17)30196-5.

6. Appelros P, Stegmayr B, Terent A. Sex differences in stroke epidemiology: a systematic review. Stroke. 2009;40(4):1082-90. https://doi.org/10.1161/ strokeaha.108.540781.

7. Roquer J, Campello AR, Gomis M. Sex differences in first-ever acute stroke. Stroke. 2003;34(7):1581-5. https://doi.org/10.1161/01.Str.0000078562.82918.F6.

8. Dehlendorff C, Andersen KK, Olsen TS. Sex disparities in stroke: women have more severe strokes but better survival than men. Journal of the American Heart Association. 2015;4(7). https://doi.org/10.1161/jaha.115.001967.

9. Sigurdsson S, Aspelund T, Kjartansson O, Gudmundsson EF, Jonsdottir MK, Eiriksdottir $\mathrm{G}$, et al. Incidence of brain infarcts, cognitive change, and risk of dementia in the general population: the AGES-Reykjavik Study (age gene/ environment Susceptibility-Reykjavik Study). Stroke. 2017:48(9):2353-60. https://doi.org/10.1161/strokeaha.117.017357.

10. Saczynski JS, Sigurdsson S, Jonsdottir MK, Eiriksdottir G, Jonsson PV, Garcia $\mathrm{ME}$, et al. Cerebral infarcts and cognitive performance: importance of location and number of infarcts. Stroke. 2009;40(3):677-82. https://doi.org/1 0.1161 /strokeaha.108.530212.

11. Aggarwal NT, Schneider JA, Wilson RS, Beck TL, Evans DA, Carli CD. Characteristics of MR infarcts associated with dementia and cognitive function in the elderly. Neuroepidemiology. 2012;38(1):41-7. https://doi. org/10.1159/000334438.

12. Riba-Llena I, Koek M, Verhaaren BF, Vrooman HA, van der Lugt A, Hofman A, et al. Small cortical infarcts: prevalence, determinants, and cognitive correlates in the general population. Int J Stroke. 2015;10(Suppl A100):1824. https://doi.org/10.1111/ijs.12543.

13. Fanning JP, Wong AA, Fraser JF. The epidemiology of silent brain infarction: a systematic review of population-based cohorts. BMC Med. 2014;12:119. https://doi.org/10.1186/s12916-014-0119-0.

14. Smith EE, Saposnik G, Biessels GJ, Doubal FN, Fornage M, Gorelick PB, et al. Prevention of stroke in patients with silent cerebrovascular disease: a scientific statement for healthcare professionals from the American Heart Association/American Stroke Association. Stroke. 2017:48(2):e44-71. https:// doi.org/10.1161/str.0000000000000116. 
15. Kovacs KR, Czuriga D, Bereczki D, Bornstein NM, Csiba L. Silent brain infarction--a review of recent observations. Int J Stroke. 2013;8(5):334-47. https://doi.org/10.1111/j.1747-4949.2012.00851.x.

16. Bokura $H$, Yamaguchi $S$, lijima K, Nagai A, Oguro H. Metabolic syndrome is associated with silent ischemic brain lesions. Stroke. 2008;39(5):1607-9. https://doi.org/10.1161/strokeaha.107.508630.

17. Leung LY, Bartz TM, Rice K, Floyd J, Psaty B, Gutierrez J, et al. Blood pressure and heart rate measures associated with increased risk of covert brain infarction and worsening leukoaraiosis in older adults. Arterioscler Thromb Vasc Biol. 2017;37(8):1579-86. https://doi.org/10.1161/atvbaha.117.309298.

18. Turin TC, Okamura T, Afzal AR, Rumana N, Watanabe M, Higashiyama A, et al. Hypertension and lifetime risk of stroke. J Hypertens. 2016;34(1):116-22. https://doi.org/10.1097/hjh.0000000000000753.

19. Kwon HM, Kim BJ, Park JH, Ryu WS, Kim CK, Lee SH, et al. Significant association of metabolic syndrome with silent brain infarction in elderly people. J Neurol. 2009;256(11):1825-31. https://doi.org/10.1007/s00415009-5201-8.

20. Kawamoto R, Tomita H, Oka Y, Kodama A. Metabolic syndrome as a predictor of ischemic stroke in elderly persons. Intern Med. 2005:44(9):9227. https://www.jstage.jst.go.jp/article/internalmedicine/44/9/44_9_922/_pdf.

21. Kwon HM, Kim BJ, Lee $\mathrm{SH}$, Choi $\mathrm{SH}$, Oh BH, Yoon BW. Metabolic syndrome as an independent risk factor of silent brain infarction in healthy people. Stroke. 2006;37(2):466-70. https:/doi.org/10.1161/01.Str.0000199081.17935.81.

22. Park K, Yasuda N, Toyonaga S, Tsubosaki E, Nakabayashi H, Shimizu K. Significant associations of metabolic syndrome and its components with silent lacunar infarction in middle aged subjects. J Neurol Neurosurg Psychiatry. 2008;79(6):719-21. https://doi.org/10.1136/jnnp.2007.134809.

23. Papagianni M, Tziomalos K. Non-alcoholic fatty liver disease: an emerging predictor of stroke risk, severity and outcome. Eur J Neurol. 2018;25(4):6101. https://doi.org/10.1111/ene.13584.

24. Karastergiou K, Smith SR, Greenberg AS, Fried SK. Sex differences in human adipose tissues - the biology of pear shape. Biol Sex Differ. 2012;3(1):13. https://doi.org/10.1186/2042-6410-3-13.

25. Link JC, Reue K. Genetic basis for sex differences in obesity and lipid metabolism. Annu Rev Nutr. 2017;37:225-45. https://doi.org/10.1146/ annurev-nutr-071816-064827.

26. Angulo P. Nonalcoholic fatty liver disease. N Engl J Med. 2002;346(16):122131. https://doi.org/10.1056/NEJMra011775.

27. [2016 Chinese guideline for the management of dyslipidemia in adults]. Zhonghua Xin Xue Guan Bing Za Zhi. 2016;44:10:833-53; doi:https://doi. org/10.3760/cma.j.issn.0253-3758.2016.10.005.

28. Grundy SM, Cleeman II, Daniels SR, Donato KA, Eckel RH, Franklin BA, et al. Diagnosis and management of the metabolic syndrome: an American Heart Association/National Heart, Lung, and Blood Institute Scientific Statement. Circulation. 2005;112(17):2735-52. https://doi.org/10.1161/circulationaha.1 05.169404 .

29. Vermeer SE, Koudstaal PJ, Oudkerk M, Hofman A, Breteler MM. Prevalence and risk factors of silent brain infarcts in the population-based Rotterdam Scan Study. Stroke. 2002;33(1):21-5.

30. Lee SC, Park SJ, Ki HK, Gwon HC, Chung CS, Byun HS, et al. Prevalence and risk factors of silent cerebral infarction in apparently normal adults. Hypertension. 2000;36(1):73-7.

31. Vermeer SE, Den Heijer T, Koudstaal PJ, Oudkerk M, Hofman A, Breteler MM. Incidence and risk factors of silent brain infarcts in the population-based Rotterdam Scan Study. Stroke. 2003:34(2):392-6.

32. Vermeer SE, Longstreth WT Jr, Koudstaal PJ. Silent brain infarcts: a systematic review. Lancet Neurol. 2007;6(7):611-9. https://doi.org/10.1016/ s1474-4422(07)70170-9.

33. Sarrafzadegan $N$, Gharipour $M$, Sadeghi M, Nezafati $P$, Talaie M, Oveisgharan $\mathrm{S}$, et al. Metabolic syndrome and the risk of ischemic stroke. J Stroke Cerebrovasc Dis. 2017;26(2):286-94. https://doi.org/10.1016/j. jstrokecerebrovasdis.2016.09.019.

34. McNeill AM, Katz R, Girman CJ, Rosamond WD, Wagenknecht LE, Barzilay JI, et al. Metabolic syndrome and cardiovascular disease in older people: the cardiovascular health study. J Am Geriatr Soc. 2006;54(9):1317-24. https:// doi.org/10.1111/j.1532-5415.2006.00862.x.

35. Iso H, Sato S, Kitamura A, Imano H, Kiyama M, Yamagishi K, et al. Metabolic syndrome and the risk of ischemic heart disease and stroke among Japanese men and women. Stroke. 2007;38(6):1744-51. https://doi.org/1 $0.1161 /$ strokeaha.106.469072
36. Matsukawa H, Shinoda M, Fujii M, Takahashi O, Yamamoto D, Murakata A, et al. Impact of body mass index on the location of spontaneous intracerebral hemorrhage. World Neurosurg. 2013;79(3-4):478-83. https://doi.org/10.1016/ j.wneu.2011.10.038.

37. Rodriguez-Campello A, Jimenez-Conde J, Ois A, Cuadrado-Godia E, GiraltSteinhauer E, Vivanco RM, et al. Sex-related differences in abdominal obesity impact on ischemic stroke risk. Eur J Neurol. 2017;24(2):397-403. https://doi. org/10.1111/ene.13216.

38. Cogswell RJ, Norby FL, Gottesman RF, Chen LY, Solomon S, Shah A, et al. High prevalence of subclinical cerebral infarction in patients with heart failure with preserved ejection fraction. Eur J Heart Fail. 2017;19(10):1303-9. https://doi.org/10.1002/ejhf.812.

39. Kalantarian S, Ay H, Gollub RL, Lee H, Retzepi K, Mansour M, et al. Association between atrial fibrillation and silent cerebral infarctions: a systematic review and meta-analysis. Ann Intern Med. 2014;161(9):650-8. https://doi.org/10.7326/m14-0538.

40. Kim SH, Shin DW, Yun JM, Lee JE, Lim JS, Cho BL, et al. Kidney dysfunction and silent brain infarction in generally healthy adults. J Neurol Sci. 2017;379: 89-93. https://doi.org/10.1016/j.jns.2017.05.043.

\section{Publisher's Note}

Springer Nature remains neutral with regard to jurisdictional claims in published maps and institutional affiliations.
Ready to submit your research? Choose BMC and benefit from:

- fast, convenient online submission

- thorough peer review by experienced researchers in your field

- rapid publication on acceptance

- support for research data, including large and complex data types

- gold Open Access which fosters wider collaboration and increased citations

- maximum visibility for your research: over $100 \mathrm{M}$ website views per year

At $\mathrm{BMC}$, research is always in progress.

Learn more biomedcentral.com/submissions 